\title{
ТЕОРЕТИКО-ПРАВОВЫЕ ПОДХОДЫ К ОПРЕДЕЛЕНИЮ ПРИНЦИПОВ ОБЕСПЕЧЕНИЯ БЕЗОПАСНОСТИ ДОРОЖНОГО ДВИЖЕНИЯ В РОССИЙСКОЙ ФЕДЕРАЦИИ
}

\begin{abstract}
Аннотация. Предметом исследования являются нормы права и научные источники, характеризующие принципы обеспечения безопасности дорожного движения. Объектом исследования являются правоотношения, складывающиеся при применении норма права, регламентирующих обеспечение безопасности дорожного движения. В результате анализа нормативно-правовых актов, научной литературы автор излагает краткое содержание принципов, которые характеризуют сущность государственного управления деятельностью по обеспечению безопасности дорожного движения, посредством анализа общеправовых принципов, принципов административного права и институциональных принципов обеспечения безопасности дорожного движения. В статье автор обращает внимание на наличие системы таких принципов. Методологическую основу исследования составил комплекс общенаучных и частнонаучных методов познания (формально-правовой, аналитический, системный метод, анализ, синтез, моделирование, сравнение и др.). В результате исследования автор делает вывод о том, что принципы обеспечения безопасности дорожного движения, заложенные в Федеральном законе "О безопасности дорожного движения» являются устойчивыми, системообразующими элементами права, позволяющие, с одной стороны, обеспечить его систематизацию, а с другой стороны обозначить специфику правовой системы, сформированной в области обеспечения безопасности дорожного движения, ее отличие от иных правовых систем современности, что позволяет отнести, рассматриваемые принципы к категории институциональных. Общим выводом автора является утверждение о концептуальной диалектической взаимосвязи институциональных принципов обеспечения безопасности дорожного движения с отраслевыми принципами и общими принчипами права. Новизна исследования состоит в комплексном анализе теоретических и правовых аспектов основополагающих идей обеспечения безопасности дорожного движения.
\end{abstract}

Ключевые слова: дорожное движение, безопасность дорожного движения, обеспечение безопасности, принципы, теория права, административное право, государственная политика, систематизация принципов, государственное управление, правоотношения.

Abstract. The research subject is the legal regulations and scientific resources, characterizing the principles of road traffic safety protection. The research object is legal relations, emerging in the process of application of legal provisions, regulating road traffic safety protection. Based on the analysis of statutory instruments and scientific literature, the author summarizes the content of the principles, characterizing the essence of public management of road traffic safety protection, by means of the analysis of general legal principles, principles of administrative law and institutional principles of road traffic safety protection. The author gives attention to the existence of the system of such principles. The research methodology is based on the set of general scientific and special research methods (formal-legal, analytical, system methods, analysis, synthesis, modeling, comparison, etc.). The author concludes that the road safety protection principles, contained in the Federal Law "On road traffic safety", are the sustainable and fundamental elements of law, helping, on the one hand, systematize the law, and on the other hand, define the specificity of the legal system, formed in the sphere of road safety protection, its difference from other modern legal systems, thus allowing considering these principles as the institutional ones. The author comes to the conclusion about the dialectical interrelation of institutional principles of road traffic safety protection and the general principles of law. The scientific novelty of the study consists in the comprehensive analysis of theoretical and legal aspects of fundamental ideas of road traffic safety protection.

Key words: public management, systematization of principles, public policy, administrative law, theory of law, principles, safety protection, road traffic safety, road traffic, legal relations. 
$\mathrm{B}$ ажное значение для правоприменительного и правореализационного процессов имеют принципы права, которые олицетворяют в себе социальную природу права, отражают закономерности его развития и используются на практике как наиболее общие ориентиры поведения.

Принципы права - это руководящие идеи, характеризующие содержание права, его сущность и назначение в обществе [1]. Они отражают наиболее важные стороны социальной деятельности общества и представляют собой своеобразный идеал.

Представители отечественной науки разрабатывают понятие, особенности и отличительные признаки правовых категорий, связанных с обеспечением безопасности дорожного движения в российской правовой науке. Несомненно, содержание элементов, характеризующих признаков исследуемых терминов трансформировалось с учетом совершенствования нормативных правовых актов, регламентирующих общественные отношения в области дорожного движения, а также с учетом развития научных представлений в указанной области [2].

Определение принципов обеспечения безопасности дорожного движения является немаловажным, так как принципы имеют огромное значения как для выстраивания целостной системы законодательства, регламентирующего общественные отношения в рассматриваемой области, так и для правоприменительного и правореализационного процессов, помогая уяснить содержание правовой нормы, ее сущность и назначение.

В правовой науке категории «принципы» уделено значительное внимание. Фундаментально изучены принципы права, принципы отдельных отраслей права, многих правовых институтов; принципы организации и деятельности правоохранительных органов, принципы законности; принципы правоприменения и юридической ответственности; принципы правосознания и др.

Несмотря на то, что большинство ученых единогласны в отношении классификации правовых принципов на общеправовые - присущие праву в целом, отраслевые - присущие отдельным отраслям права и межотраслевые - принадлежащие группе смежных отраслей права, необходимо отметить значительную вариативность в количестве, наименовании, содержании и научных подходах к систематизации принципов, относящихся к теории права. То есть, когда представители науки характеризуют конкретный перечень общеправовых принципов, то каждый автор имеет свое собственное мнение.

В частности, С. С. Алексеев выделяет следующие общеправовые принципы: законности, справедливости, юридического равенства, социальной свободы, гражданского долга, объективной истины, ответственности за вину [1]. В. В. Лазарев относит к общеправовым принципам следующие основополагающие начала: гуманизма, равенства граждан перед законом, демократизма, законности, справедливости [3]. А. С. Пиголкин указывает на следующие общеправовые принципы: демократизм, гуманизм, законность, равноправие, установление обеспечение и охрана прав личности, справедливость, обеспечение верховенства закона и др. [4].

Становится очевидно, что, несмотря на разнообразие научных подходов к отнесению того или иного принципа к категории общеправовых, указанное разнообразие стало возможным благодаря авторскому пониманию отражения социальных, правовых, экономических и иных закономерностей развития общества и выделения их в основные социальные ценности.

Обеспечение безопасности дорожного движения, будучи сложным (по элементному составу) и многогранным (по функциям) общественным явлением не представляет собой самоуправляемую систему общества, а основано на организующем и регулирующем воздействии государства (через систему своих структур) на общественные отношение в рассматриваемой сфере, то есть на государственном управлении.

Исследуя содержание принципов в государственном управлении, Г. В. Атаманчук отмечает, что в научной литературе приводится множество не только самых разнообразных, зачастую не стыкующихся между собой принципов, но и примеров их систематизации. При этом он предлагает систематизацию принципов государственного управления отдельными группами:

1) общественно-политические принципы;

2) функционально-структурные принципы;

3) организационно-структурные принципы;

4) принципы государственно-управленческой деятельности [5].

Соответственно, в силу разнообразия и широты регулируемых общественных отношений, связанных с обеспечением безопасности дорожного движения, выделенные Г. В. Атаманчук принципы государственного управления, относятся в полной мере к государственной политике, проводимой Российской Федерацией, связанной с обеспечением безопасности дорожного движения (с позиции управляющего аспекта) а по содержанию, сущности и своему назначению в правовых нормах, относятся к группе межотраслевых принципов.

Несомненно, говоря о обеспечении безопасности дорожного движения, необходимо отметить, что значительная часть правоотношений в рассматриваемой области юридически урегулирована нормами административного права, которое выражает публично-правовые интересы, то есть государственные интересы в такой сфере общественной жизни, как безопасность дорожного движения. 


\section{Административное и муниципальное право 11 (107) • 2016}

В административном праве не имеют прямого закрепления его общие и отраслевые принципы (исключение производство по делам об административных правонарушениях, законодательство о государственной службе) [6]. Основные принципы административного права могут быть выделены при анализе Конституции РФ и совокупности нормативных правовых актов. Исследуя принципы административного права, необходимо отметить, что, как и в отношении общеправовых принципов права, наблюдается отсутствие единых подходов в количестве принципов их наименовании и содержании.

Справедлива позиция В. А. Юсупова, который характеризуя принципы административного права классифицирует их на общие принципы и принципы его институтов [7]. Общие принципы административного права отражают сущность права, раскрывают общий характер управленческой, исполнительно-распорядительной и других видов административной деятельности органов исполнительной власти и их государственных служащих, а также закономерности создания и развития механизма правового регулирования, в нашем случае правоотношений, связанных с безопасностью дорожного движения.

К тому же, многие административно-правовые институты обладают собственными принципами (институциональными), которые характеризуют наиболее существенные стороны конкретной правовой системы на уровне правовых отношений, определяя содержание сложных взаимоотношений внутри данной системы, конкретизируя, уточняя и развивая действие общих принципов административного права [8].

Анализ современных научных позиций ученых в области административного права позволяет выделить их представителей, которые определяют исключительно общие принципы административного права на основе анализа Конституции Российской Федерации. В частности, Л. Л. Попов указывает, что право, выполняя свои функции, руководствуется основными принципами, общими с теми, на базе которых происходит реализация исполнительной власти, при этом основополагающее значение имеют из них те, которые закреплены в Конституции РФ: приоритет личности и ее интересов, разделения властей, федарализма, законности, гласности, ответственности [9]. А. П. Алехин и А. А. Кармолицкий к указанным принципам добавляют принцип единства системы исполнительной власти в Российской Федерации [10]. А. П. Коренев выделяет следующие основные принципы административного права: демократизм, нормотворчество и реализации права, равенство граждан перед законом и правоприменителем, взаимная ответственность государства и личности, федерализм, гуманизм, законность [11].
Конечно же, обеспечение безопасности дорожного движения осуществляется на правовой основе и нормы права, регламентирующие, указанную деятельность не противоречат Конституции Российской Федерации, тем более рассматривая обеспечение безопасности дорожного движения как целенаправленную, системную, межведомственную деятельность субъектов управляющего воздействия на исследуемые правоотношения, выраженную в проведении государственной политики в области дорожного движения, представляется возможным утверждать, что в ее основе лежат конституционные принципы.

Ю. А. Тихомиров выделяет принципы административного права, основываясь на критериях регулирования нормами права правоотношений, связанных с закономерностями государственного управления и функционирования исполнительной власти, и относит к принципам административного права: подзаконность деятельности; иерархичность построения субъектов и их отношений; участие граждан и их объединений в государственном управлении; функционально- специализированный характер деятельности; осуществление властных полномочий профессиональным, постоянно действующим аппаратом и его служащими [12].

Следует отметить, что в современной теории права наиболее широкий перечень принципов административного права исследован в трудах Ю. Н. Старилова, который соглашаясь с позицией В. А. Юсупова, о классификации принципов административного права на общие принципы и принципы его институтов, дополнительно классифицирует их на конституционные (политико-юридические) и организационные принципы [8]. Основным назначением принципов административного права является установление характера административно-правового регулирования конкретных общественных отношений, закрепление особого порядка реализации субъективных прав, обязанностей, полномочий соответствующих субъектов административного права [8], что является в полной мере применимым к общественным отношениям, связанным с обеспечением безопасности дорожного движения.

К конституционным принципам административного права, являющимся конституционно-правовыми основами обеспечения безопасности дорожного движения относятся:

- Принцип законности, который проявляется в следующих аспектах. Во-первых, рассматриваемый принцип предопределяет верховенство Конституции РФ и федеральных законов над иными нормативными правовыми актами, устанавливающими правовые основы функционирования системы государственного управления деятельностью по обеспечению безопасности дорожного движения. Во-вторых, правовые акты 
в области безопасности дорожного движения должны соответствовать Конституции РФ, общепризнанным принципам и нормам международного права. В-третьих, органы исполнительной власти, местного самоуправления, юридические лица, должностные лица и граждане обязаны соблюдать нормы права, регламентирующие правоотношения в рассматриваемой области.

- $\quad$ Принцип приоритета прав и свобод человека и гражданина, их непосредственного действия и правовой защиты. Наивысшей ценностью нашего государства является человек, его права и свободы. Признание, соблюдение и защита прав и свобод человека и гражданина - обязанность государства. Провозглашенные в Основном законе страны права и свободы являются обязательными для обеспечения их реализации со стороны государства.

- Принцип федерализма, выражающийся в единстве системы государственной власти, притворяемой посредством разграничения предметов ведения между Российской Федерацией и субъектами Российской Федерации в области обеспечения безопасности дорожного движения. Несмотря на то, что в содержании рассматриваемого принципа взаимодействуют два уровня федеративной системы - Российская Федерация, представляемая федеральными органами государственной власти и субъекты России, представляемые органами государственной власти этих субъектов, тем не менее, Федеральный закон «О безопасности дорожного движения», выходя за рамки данного принципа, в статье 6 проводит разграничение предметов ведения дополнительно и в отношении органов местного самоуправления.

- Принцип разделения законодательной, исполнительной и судебной властей. В теории права выделяют обозначенные три основные функции государственной власти, каждая из которых исполняется самостоятельным органом государственной власти. Разделение властей подчеркивает их независимость, самостоятельность и способствует беспрепятственному осуществлению всеми ветвями власти своих функций. Административное право сферу своего регулирования распространяет преимущественно на общественные отношения, складывающиеся в системе исполнительной ветви государственной власти.

- $\quad$ Принцип обеспечения права граждан на участие в государственном управлении, его так же называют принципом эффективного управления или народовластия. Указанный принцип реализуется посредством предоставления возможности гражданам Российской Федерации их объ- единениям принимать непосредственное (через референдум) или опосредованное (через избираемые органы государственной власти и местного самоуправления) участие в управлении делами государства, тем самым осуществлять власть народа (например, формировании норм административного права). Интересна формулировка части 4 статьи 32 Основного закона, предусматривающая в числе публичных форм участия граждан в управлении государством посредством такого института, как формирование государственного аппарата (равный доступ к государственной службе). Тем самым, граждане имеют возможность находиться на конкретных должностях органов исполнительной власти и непосредственно оказывать влияние на общественные отношения, связанные с обеспечением безопасности дорожного движения.

- Принцип равенства граждан перед законом выражается в том, что государство гарантирует независимо от пола, расы, происхождения, языка, национальности, отношения к религии, имущественного и должностного положения, убеждений, принадлежности к общественным объединениям, а также других обстоятельств, равное правовое положение. Все граждане равны перед законом и судом.

- Принцип гуманизма выражается в признания приоритета общечеловеческих ценностей (права и свободы человека) в системе управленческих отношений с государством. Особую актуальность, рассматриваемый принцип приобретает при построении административноправовых отношений между гражданином, обществом и государством при реализации норм административно-деликтного права, применении административного принуждения и административной ответственности.

Организационные принципы административного права отражают порядок построения и функционирования органов исполнительной власти в механизме государственного управления деятельностью по обеспечению безопасности дорожного движения, системе государственных органов и ее звеньев, обеспечения их эффективной административной деятельности.

Организационные (организационно-функциональные) принципы административного права, характеризующие механизм государственного управления деятельностью по обеспечению безопасности дорожного движения:

- Принцип вертикальной подчиненности в системе управления. Иными словами, данный принцип называют принцип подконтрольности (поднадзорности) и подотчетности государственных органов и, что немало важно, 
государственных служащих. В системе обеспечения безопасности дорожного движения, задействовано значительное количество органов государственной власти со своей иерархией подчинённости, которые осуществляют выполнение своих функциональных обязанностей в соответствии с требованиями многочисленных нормативных правовых актов, а контроль (надзор) за их исполнением является важнейшей функцией государственного управления общественными отношениями в области дорожного движения.

- Принцип единства основных требований, предъявляемых к государственному управлению. Требования, установленные в нормативных правовых актах должны быть едиными как к управлению органами, реализующим государственную политику в области обеспечения безопасности дорожного движения, так и к государственным служащим, задействованных в рассматриваемых общественных отношениях.

- Принцип профессионализма и компетентности государственных служащих олицетворяет в себе совокупность важнейших требований, определяющих необходимость наличия специализированных знаний умений и навыков, необходимых для практической деятельности сотрудников, но и необходимое правовое условие, предоставляющее право на осуществление должностных полномочий.

- Принцип гласности в осуществлении деятельности по обеспечению безопасности дорожного движения. Государство, в целях обеспечения достоверности, справедливости и очевидности реализации заявленных целей и задач, связанных с безопасностью дорожного движения, обеспечивает открытость информации об осуществляемой деятельности. Принцип гласности гарантирует возможность влияния граждан на само государство и его органы власти. Реальным примером рассматриваемых правоотношений является деятельность Общественного совета при МВД России и Общественного совета Минтранса России.

- Принцип ответственности государственных органов за принятые административные акты (решения). Государство, а также его органы и должностные лица обязаны соблюдать и защищать права и свободы человека и гражданина, поэтому их решения, обличенные в нормативные правовые акты должны соответствовать нормам законов, отвечать требованиям целесообразности и должны соответствовать общему вектору осуществляемой деятельности по обеспечению безопасности дорожного движения, а виновные лица нести ответственность за халатные либо не компетентные решения.

- Принцип обязательного учета научных основ организации государственного управления деятельностью по обеспечению безопасности дорожного движения. При построении целостной системы обеспечения безопасности дородного движения, для ее эффективного функционирования необходимо основываться на современных достижениях науки и техники различных областей научного знания, с учетом развития, единства, взаимосвязи и взаимообусловленности явлений, происходящих в области дорожного движения.

Конечно же, обеспечение безопасности дорожного движения является комплексной задачей, которая решается не только административно-правовыми средствами, а также уголовно-правовыми и гражданско-правовыми. В силу чего, на общественные отношения в области дорожного движения оказывают влияние нормы указанных отраслей права, которым присущи свои отраслевые принципы. Однако, основное содержание правовых норм отраслей права базируется на общеправовых (конституционных) принципах которые, несомненно, легли в основу нормативных правовых актов, регламентирующих общественные отношения в области дорожного движения, а принципы административного права интегрируют широкий спектр правоотношений управленческого характера, в том числе, и деятельность государства по обеспечению безопасности дорожного движения.

Обращаясь к анализу положений Федерального закона от 10 декабря 1995 г. № 196-ФЗ «0 безопасности дорожного движения» необходимо отметить, что в статье 3 закреплены основные принципы обеспечения безопасности дорожного движения, которые являются предметными, специализированными, по отношению к общеправовым:

1. Приоритет жизни и здоровья граждан, участвующих в дорожном движении, над экономическими результатами хозяйственной деятельности. Указанный принцип основывается на положениях статьи 2 Конституции Российской Федерации, провозглашающей человека, его права и свободы высшей ценностью нашего демократического государства и выделяющий Конституционную обязанность государства, связанную с признанием, соблюдением и защитой прав и свобод человека и гражданина. Кроме того, положения статьи 20 Основного закона закрепляют, что каждый имеет право на жизнь, отсюда следует, что жизнь рассматривается как неотъемлемое право и подчеркивается взаимосвязь взаимоотношений государства с системой защищаемых ценностей, в иерархии которых именно человеку с его правами 
и свободами принадлежит главенствующее, доминирующее положение [13]. Тем самым, указанные конституционные принципы, находятся в тесной интерпретации с принципами обеспечения безопасности дорожного движения, соответственно жизнь и здоровье граждан являются приоритетом обеспечения и защиты государства, над результатами экономической и хозяйственной деятельности Российской Федерации.

2. Приоритет ответственности государства за обеспечение безопасности дорожного движения над ответственностью граждан, участвующих в дорожном движении. Для всех отраслей права является характерным принцип ответственности, что позволяет отнести его к категории универсальных принципов, в том числе и к принципам обеспечения безопасности дорожного движения. В свою очередь, принцип ответственности имеет широкую сферу применения, так как направлен на обеспечение соблюдения не только норм административного законодательства, но и иных отраслей права, применяемых в равной степени к участникам дорожного движения.

Вместе с тем, содержание принципа ответственности применительно к сфере обеспечения безопасности дорожного движения изложено с учетом закрепления приоритета ответственности государства за обеспечение безопасности в исследуемой области, над ответственностью граждан. Тем самым, государство возлагает на себя обязанность по обеспечению безопасности дорожного движения за счет создания соответствующего правового механизма обеспечения безопасности. В широком смысле интересы личности по участию в безопасном дорожном движении, являются и интересами государства в создании условий, позволяющих обеспечить желаемую безопасность. Государство, в свою очередь, реализуя указанный принцип, определяет, как нормотворческую, так и правоприменительную деятельность по обеспечению безопасности дорожного движения, координирует функционирование существующего механизма правового регулирования, формирует правовое мышление и правовую культуру в исследуемой области.

3. Соблюдение интересов граждан, общества и государства при обеспечении безопасности дорожного движения.

По своему содержанию данный принцип продолжает раскрывать смысловую нагрузку предыдущих принципов о защите прав и законных интересов участников дорожного движения (граждан), интересы которых необходимо рассматривать в тесной взаимосвязи с интересами общества и самого государства. Основные ориентиры развития, которого, с использованием современных подходов к обеспечению безопасности государства и без- опасности дорожного движения нашли отражение в Стратегии национальной безопасности Российской Федерации [14], Концепции долгосрочного социально-экономического развития Российской Федерации на период до 2020 года [15] и иных нормативных правовых актах, рассчитанных на долгосрочную перспективу.

Соблюдение интересов граждан, то есть соблюдение их прав и свобод, является обязанностью государства, но в данном случае необходимо рассматривать соблюдение интересов граждан с позиции определенного баланса между интересами гражданина, общества в лице иных участников дорожного движения и государства. При этом взаимоотношения гражданина и государства не замыкаются к обязанности государства не посягать на права человека. Такое восприятие содержания соблюдения баланса между интересами гражданина, общества и государства является оправданным и основывается на использовании системы мер «сдержек и противовесов», поскольку реальная свобода интересов личности (гражданина) должна выражаться в реализации предоставленных ей прав в рамках предписаний нормативных правовых актов, иначе возникает наличие дисбаланса, что, в свою очередь, ведет к возникновению угроз как в целом безопасности дорожного движения, так и обществу и отдельным индивидам - участникам дорожного движения.

4. Программно-целевой подход к деятельности по обеспечению безопасности дорожного движения.

Каждый из рассмотренных принципов обеспечения безопасности дорожного движения имеет соответствующую интерпретацию, однако совокупность основополагающих идей является своеобразным связующим звеном между правовой системой обеспечения безопасности дорожного движения и основными закономерностями развития и функционирования общества и общественных отношений в исследуемой сфере.

С помощью принципов, правовая система обеспечения безопасности адаптируется к главенствующим интересам и потребностям человека и общества. Однако, достижение идеала обеспечения безопасности дорожного движения, связанного с полным устранением проблем обеспечения безопасности дорожного движения, является своеобразной иллюзией. Вместе с тем, государство обязано выполнить все возможное для обеспечения реализации прав и свобод человека и гражданина, их законных интересов, посредством принятия комплекса действенных мер направленных на устранение существующих проблем обеспечения безопасности дорожного движения.

Достижение указанных результатов возможно на основе совместной деятельности всех субъектов управляющего воздействия на общественные 


\section{Административное и муниципальное право 11 (107) • 2016}

отношения в области дорожного движения, посредством реализации комплекса мероприятий по обеспечению безопасности на основе программно-целевого подхода, который находит свое выражение в разработке и принятии федеральных целевых программ повышения безопасности дорожного движения и принятых на их основе региональных и муниципальных программ.

Несмотря на то, что рассматриваемый принцип сформирован с момента принятия Федерального закона «0 безопасности дорожного движения», тем не менее, нормативно-правовое претворение в «жизнь» данного принципа стало возможным лишь в 2006 году с принятием федеральной целевой программы «Повышение безопасности дорожного движения в 2006-2012 гг.». В этом отношении справедливо отмечает Г. В. Атаманчук, который рассматривая принципы, указывает, что их нельзя просто выдвигать, что в правовой науке встречается довольно часто, принципам нельзя произвольно давать те или иные названия, как и нельзя, думать, что они могут действовать автоматически [16].

Результаты реализации, указанной федеральной целевой программы показали эффективность проводимой государственной политики в области обеспечения безопасности дорожного движения, тем самым программно-целевой подход явился синтезирующим принципом, объединившим идеологические основы происхождения, становления и реализации правовых, фундаментальных основ проводимых мероприятий по обеспечению безопасности дорожного движения. Оправданность и целесообразность реализации программно-целевого подхода позволила продолжить реализацию комплекса мероприятий по предупреждению причин возникновения дорожно-транспортных происшествий и снижению тяжести их последствий, выраженных в федеральной целевой программе «Повышение безопасности дорожного движения в 2013-2020 годах».

Таким образом, принципы обеспечения безопасности дорожного движения, заложенные в Федеральном законе «0 безопасности дорожного движения» являются устойчивыми, системообразующими элементами права, позволяющие, с одной стороны, обеспечить его систематизацию, а с другой стороны обозначить специфику правовой системы, сформированной в области обеспечения безопасности дорожного движения, ее отличие от иных правовых систем современности, что позволяет отнести, рассматриваемые принципы к категории институциональных.

Вместе с тем, хотя принципы права и представляют собой отчасти субъективные понятия, законодательная формулировка отдельных принципов права является не бесспорной. В частности, несмотря на общее понимание приоритета жизни и здоровья человека над какими бы то ни было результата- ми деятельности государства, Федеральный закон «0 безопасности дорожного движения» в основополагающих началах ориентирован на защиту жизни, здоровья, прав и законных интересов именно гражданина, а не человека. Хотя, говоря о безопасности дорожного движения, и принципах ее обеспечения, с позиции основных идей и руководящих положений, которые определяют содержание и направления правового регулирования обеспечения рассматриваемой безопасности, представляется не совсем уместным, ориентироваться на гражданина, так как участником процесса дорожного движения может выступать человек, обладающим иным правовым статусом (например, гражданин другого государства, лицо без гражданства), в силу чего, возникает потребность в упорядочивании взаимоотношений личности и государства, которое призвано в соответствии с Конституцией Российской Федерации обеспечить защиту прав его и законных интересов посредством использования термина «человек».

Кроме того, в теории права отражено, что целевое назначение принципов позволяет преломить правовую систему к основным потребностям, как индивида, так и общества в целом, в результате чего, система становится совместимой с ними [1]. Несмотря на это, в отдельных нормативных правовых актах намечена тенденция, связанная с формулированием отдельных принципов, содержание которых выходит за рамки классической модели построения традиционной составляющей понятия «принципы». Так, в статье 3 Федерального закона Российской Федерации от 9 февраля 2007 года № 16-ФЗ «О транспортной безопасности» в качестве основных принципов обеспечения транспортной безопасности закреплен принцип взаимной ответственности личности, общества и государства в области обеспечения транспортной безопасности. Тем самым, ответственность государства, в лице его органов исполнительной власти, связанная с реализацией функции по выработке государственной политики и правовому регулированию в сфере транспорта, ставится в один уровень с ответственностью гражданина, который является рядовым участником правоотношений в сфере транспорта, что не соответствует современным потребностям нашего государства, сложившейся правовой культуре и функциональному предназначению категории «принцип», так как руководящая роль в проведении системной деятельность в вопросах обеспечения транспортной безопасности принадлежит государству, ответственность которого должна быть приоритетной перед ответственностью гражданина.

В современной правовой системе и общественных отношениях, урегулированных ей, в последнее время все больше прослеживаются отдельные тенденции отклонения от состояния незыблемости и постоянства к некоему состоянию условности. В част- 
ности, В.С. Афанасьев указывает, что принцип выступает как идеальная форма законности, соблюдать нормы права должны все, но в действительности имеет место немало нарушений законности, и возникает понятие состояния (уровня) законности» [17].

Существующие понятия, зависимые от количественных показателей - состояние (уровень) законности, состояние безопасности отражают указанные общественные, социальные явления. Однако, говоря о принципе законности в области обеспечения безопасности дорожного движения необходимо придержи- ваться качественных (незыблемых) характеристик принципов их сущности и назначения в обществе, как руководящих идей, а не состояния явлений.

Проведенный анализ соотношения принципов обеспечения безопасности дорожного движения с теоретическими подходами к принципам права, позволяет сделать вывод о концептуальной диалектической взаимосвязи институциональных принципов обеспечения безопасности дорожного движения с отраслевыми принципами и общими принципами права.

\section{Библиография:}

1. Терия государства и права: Учебник / Алексеев С.С., Архипов С.И. и др. 2-е изд., перераб. и доп. М.: Норма, 2005. 496 с.

2. Калюжный Ю.Н. Основные научные подходы к пониманию понятия «дорожное движение» / Вестник Калининградского филиала Санкт-Петербургского университета МВД России. 2016. № 1 (43). С. 31-33.

3. Общая теория права и государства: Учебник / Под ред. В.В. Лазарева. 3-е изд., перераб. и доп. М.: Юристъ, 2001.520 с.

4. Теория государства и права: Учебник / Под ред. А.С. Пиголкин. М.: Городец, 2003. 544 с.

5. Атаманчук Г.В. Теория государственного управления: курс лекций. М., 1997. С. 266-277.

6. Алехин А.П., Кармолицкий А.А. Административное право России: Учебник. М.: Зерцало, 2006. С. 19.

7. Теория административного права / Юсупов В.А. М.: Юрид. лит., 1985. 160 с.

8. Старилов Ю.Н. Курс общего административного права. В 3 т. Т. І: История. Наука. Предмет. Нормы. Субъекты. М.: Издательство НОРМА (Издательская группа НОРМА- ИНФРА М), 2002. С. 368.

9. Административное право: Учебник / Под ред. Л.Л. Попова. М.: Юристъ, 2002. 697 с.

10. Алехин А.П., Кармолицкий А.А. Административное право России: Учебник. М.: Зерцало, 2006. С. 19-22.

11. Коренев А.П. Административное право России. Учебник. В 3-х частях. Часть І. М.:, Изд-во «Щит-М», 1999. С $32-35$.

12. Тихомиров Ю.А. Административное право и процесс: полный курс. М.: 2001. 652 с.

13. Комментарий к Конституции Российской Федерации / Под ред. В.Д. Зорькина 2-е изд., пересмотр (статьи 5, 11, 66, 71-73, 83, 84, 90, 136, 137). Норма: Инфра-М Москва, 2011. - С. 1008.

14. Указ Президента Российской Федерации от 31 декабря 2015 № 683 «0 Стратегии национальной безопасности Российской Федерации» // Консультант Плюс: [Электронный ресурc]. http://www.consultant.ru

15. Концепция долгосрочного социально-экономического развития Российской Федерации на период до 2020 года, утвержденная распоряжением Правительства Российской Федерации от 17 ноября 2008 г. № 1662-р // Консультант Плюс: [Электронный ресурc]. http://www.consultant.ru

16. Атаманчук Г.В. Теория государственного управления: курс лекций. М., 2004. С. 141-143.

17. беспечение прав человека в деятельности органов внутренних дел / под ред. Ю.В. Анохина, В.Н. Бутылина. С. 224.

\section{References (transliterated):}

1. Teoriya gosudarstva i prava: Uchebnik / Alekseev S.S., Arkhipov S.I. i dr. 2-e izd., pererab. i dop. M.: Norma, 2005. 496 s.

2. Kalyuzhnyi Yu.N. Osnovnye nauchnye podkhody k ponimaniyu ponyatiya «dorozhnoe dvizhenie» / Vestnik Kaliningradskogo filiala Sankt-Peterburgskogo universiteta MVD Rossii. 2016. № 1 (43). S. 31-33.

3. Obshchaya teoriya prava i gosudarstva: Uchebnik / Pod red. V.V. Lazareva. 3-e izd., pererab. i dop. M.: Yurist", 2001.520 s.

4. Teoriya gosudarstva i prava: Uchebnik / Pod red. A.S. Pigolkin. M.: Gorodets, 2003. 544 s.

5. Atamanchuk G.V. Teoriya gosudarstvennogo upravleniya: kurs lektsii. M., 1997. S. 266-277.

6. Alekhin A.P., Karmolitskii A.A. Administrativnoe pravo Rossii: Uchebnik. M.: Zertsalo, 2006. S. 19.

7. Teoriya administrativnogo prava / Yusupov V.A. M.: Yurid. lit., 1985. $160 \mathrm{c}$.

8. Starilov Yu.N. Kurs obshchego administrativnogo prava. V 3 t. T. I: Istoriya. Nauka. Predmet. Normy. Sub"ekty. M.: Izdatel'stvo NORMA (Izdatel'skaya gruppa NORMA- INFRA M), 2002. S. 368.

9. Administrativnoe pravo: Uchebnik / Pod red. L.L. Popova. M.: Yurist", 2002.697 s.

10. Alekhin A.P., Karmolitskii A.A. Administrativnoe pravo Rossii: Uchebnik. M.: Zertsalo, 2006. S. 19-22.

11. Korenev A.P. Administrativnoe pravo Rossii. Uchebnik. V 3-kh chastyakh. Chast' I. M.:, Izd-vo «Shchit-M», 1999. S 32-35.

12. Tikhomirov Yu.A. Administrativnoe pravo i protsess: polnyi kurs. M.: 2001. $652 \mathrm{~s}$.

13. Kommentarii k Konstitutsii Rossiiskoi Federatsii / Pod red. V.D. Zor'kina 2-e izd., peresmotr (stat'i 5, 11, 66, 71-73, 83, 84, 90, 136, 137). Norma: Infra-M Moskva, 2011. - S. 1008.

14. Ukaz Prezidenta Rossiiskoi Federatsii ot 31 dekabrya 2015 № 683 «O Strategii natsional'noi bezopasnosti Rossiiskoi Federatsii» // Konsul'tant Plyus: [Elektronnyi resurs]. http://www.consultant.ru

15. Kontseptsiya dolgosrochnogo sotsial'no-ekonomicheskogo razvitiya Rossiiskoi Federatsii na period do 2020 goda, utverzhdennaya rasporyazheniem Pravitel'stva Rossiiskoi Federatsii ot 17 noyabrya 2008 g. № 1662-r // Konsul'tant Plyus: [Elektronnyi resurs]. http://www.consultant.ru

16. Atamanchuk G.V. Teoriya gosudarstvennogo upravleniya: kurs lektsii. M., 2004. S. 141-143.

17. Obespechenie prav cheloveka v deyatel'nosti organov vnutrennikh del / pod red. Yu.V. Anokhina, V.N. Butylina. S. 224 